\title{
Determination of the Fatty Acids in Fish Tissue and Feed - Comparison of Different Methods and Statistical Evaluation
}

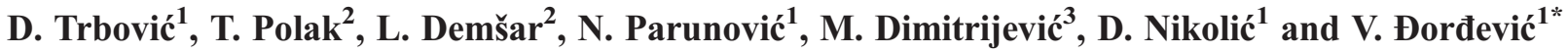 \\ ${ }^{1}$ Institute of Meat Hygiene and Technology, Kaćanskog 13, 11000 Belgrade, Serbia \\ ${ }^{2}$ University of Ljubljana, Biotechnical Faculty, Department of Food Science and Technology, \\ Jamnikarjeva 101, 1000 Ljubljana, Slovenia \\ ${ }^{3}$ University of Belgrade, Faculty of Veterinary Medicine, Bulevar oslobođenja 18, 11000 Belgrade, Serbia
}

Received: 09 November 2016; accepted: 26 November 2016

\begin{abstract}
With the aim to reinforce laboratory competence in the field of testing the quality of fish from aquaculture, a study on the precision of fatty acid (FA) analyses in fish meat and fish feed was undertaken. Different methods were performed in laboratories. In situ transesterification method and extraction of lipids from the fish were followed by capillary gas chromatography with flame ionization detection. The reproducibility $(R)$ values of the majority of FAs were less than $3 \%$ of their absolute values. Differences in calculating ionization detector response factors and/or autoxidation caused by faulty sample-handling could lead to variation in quantification of FAs in fish, especially for FA C22:6n-3. Statistical analysis showed a significant correlation between the two laboratories' quantifications of FAs in fish and fish feed (Pearson's correlation coefficient; $r=0.987, r=0.994$, and $r=0.997$; for fish $\mathrm{Z}$ [trout], fish $\breve{\mathrm{S}}$ [rainbow trout], and fish feed, respectively). Overall, adequate accuracy was obtained in this study. The proposed method provides a fast and efficient means of identifying fish and feed for quality control purposes.
\end{abstract}

Keywords: Fish tissues, fatty acids, quantitation, gas chromatography, reproducibility

\section{Introduction}

Fish diet has a major impact on the chemical composition of fish tissues and especially on the fatty acid (FA) composition of the fish lipids [1-4]. The FA composition of fish can also be influenced by environmental factors such as a temperature, water quality, season, and the size and age of the fish [5-10]. The impact of diet on the FA composition in fish tissue has been examined in numerous farmed and wild fish species [5, 11, 12]. Determination of the FAs in fish and marine oils is predominantly performed by gas chromatographic methods after methylation and detects corresponding methyl esters [13-16]. Separation can be obtained on different columns, and quantification is usually performed using internal standards [17, 18].

Extraction of lipids is a prevailing problem for accurate determination of FA composition and depends on the binding of FAs to the matrix of the sample. There are various extraction methods with different types of solvents or solvent mixtures to isolate lipids from tissues. One of the most widely used methods for the extraction of lipids is that proposed by Soxhlet [19-21]. The method is simple and efficient, and the main disadvantage is its long duration and use of large amounts of solvent, usually petroleum ether. Other methods were proposed by Folch et al. [22], Blight and Dyer [23], and Hara and Radin [24], and there are also more contemporary extraction methods such as pressurized liquid extraction (PLE) and accelerated solvent extraction (ASE) [25, 26]. Some researchers have prepared in situ direct methylation of FAs without lipid extraction and purification steps [27-30].

There are various procedures for the esterification of FAs that can be applied to different classes of lipids [13], and which vary in require expenditure of time and effort. However, absolute accuracy in such studies is not the ultimate priority. The main problem for the analysis of $n-3$ polyunsaturated fatty acids (PUFAs) is that PUFAs are rather unstable, so that calibration cannot be

* Author for correspondence: vesna@inmesbgd.com performed using quantitative standards. The other problem concerns the use of detector response factors. When flame ionization detectors are used, small correction factors can be applied, when high precision is required, to compensate for the fact that the carboxyl carbon atom in each ester is not appreciably ionized during combustion [13]. There are also small effects of this kind due to the absence of hydrogen atoms at double bonds. The degree of correction necessary is greatest for FAs of shorter chain length or with a high degree of unsaturation. Whereas some analysts use empirical response factors (ERFs), other trust in theoretical response factors (TRFs), but many do not use correction factors at all [31-33]. Careful calibration with pure standards is necessary in this instance. When an analysis has been completed, the results can be expressed directly as weight percentages of the FAs. High accuracy of gas chromatography for FA quantitative composition was completely reviewed by Bannon et al. [33], Craske and Bannon [32], and Ackman [31].

Inter-laboratory tests are a useful tool to detect systematic errors associated with a specific method or inadequate application of the method in the laboratory [34]. Unacceptable differences may exist between supposedly identical measurements that are performed in different laboratories. Thus, the important question that has to be answered in the evaluation of analytical methods is how much between-laboratory variability exists [34]. Analysts can very well check between-laboratory variability, but other analysts cannot be verified in other laboratories. This situation suggests that results of analysis of reference standards can vary from laboratory to laboratory [35].

Quality control of food analysis is of great importance because only precise analytical results can allow valid assumptions to be drawn between the quality of different types of food and the risks associated with human activities [36]. In many cases, the analyses used can lack the required quality. Generally, in addition to errors associated with sampling, there are three sources of errors which can occur in the analysis: the pretreatment of the sample (digestion, extraction), the final measurement (calibration error,

This is an open-access article distributed under the terms of the Creative Commons Attribution-NonCommercial 4.0 International License (https://creativecommons.org/licenses/by-nc/4.0/), which permits unrestricted use, distribution, and reproduction in any medium for non-commercial purposes, provided the original author and source are credited, a link to the CC License is provided, and changes - if any - are indicated. 
overlapping peaks), and insufficient experience (lack of training, careful work, pure vessels and equipment) [37].

Numerous comparative studies have been conducted with different aims, e.g., to test different methods of analysis [38, 39], to determine the suitability for application of one or more methods [40], to establish precision of the methods by determining their reproducibility limits and make recommendation for their use in laboratory practice $[41,42]$, to evaluate and possibly improve analytical methods or laboratory performance, or to certify reference materials [43-45]. Due to the heterogeneity of FAs in animal fats, it is also necessary to study the extraction and derivatization procedure in order to obtain accurate quantitative and qualitative results [38].

With the aim to reinforce laboratory competence in the field of testing the quality of fish from aquaculture, a study on the precision of two differing analytical methods for quantitative determination of FAs in fish meat and fish feed was undertaken. The results of the FA compositions and total lipids were compared in trout (Salmo truta) and rainbow trout (Oncorhynchus mykiss), and fish feed with different methods in two laboratories. The precision of laboratories participating in this comparative study was determined, and reproducibility was compared. The real aim of this study was to achieve a practical inter-changeability of the test results.

\section{Materials and Methods}

Sample Preparation. Two representative fish samples meat without bones of trout (Z) (Salmo truta) and rainbow trout $(\check{S})$ (Oncorhynchus mykiss) and one sample of fish feed were prepared for analysis in accordance with International Organization for Standardization (ISO) standard method [46]. The samples were homogenized by using a homogenizer Grindomix GM 200 (Retch, Germany) at 5000-6000 rpm for $20 \mathrm{~s}$ and stored under vacuum in plastic bags at $-18^{\circ} \mathrm{C}$ until use. Participants were required to determine the content of total lipids and FA composition by the most appropriate methods of their choice. Participants were requested to report results in duplicate in $\mathrm{g} / 100 \mathrm{~g}$ of FA to two significant figures or two decimal places, whichever was appropriate. Analytical results were exchanged via correspondence. Laboratories were requested to report their uncertainties as standard deviations of two measurements.

FA Analysis by Capillary Gas Chromatography by Method 1. Total lipids in fish feed were determined by the ISO standard method [20]. Lipids were extracted from the fish feed with petroleum ether (boiling point ranged from 40 to $60{ }^{\circ} \mathrm{C}$ ) after acid hydrolysis of the sample with hydrochloric acid. Total lipids in fish for determination of FA were first extracted with a mixture of $n$-hexane and iso-propanol $(60,40, \mathrm{v} / \mathrm{v})$ by accelerated solvent extraction at $100{ }^{\circ} \mathrm{C}$, under nitrogen at 10.3 MPa (ASE 200, Dionex, Sunnyvale, CA, USA). The extracts were collected, and the solvent was removed under a stream of nitrogen (Dionex Solvent evaporator 500, Sunnyvale, CA, USA), at $50{ }^{\circ} \mathrm{C}$, until dryness. Fatty acid methyl esters (FAMEs) were prepared by dissolving lipid extract with tertbutyl methyl ether. Transesterification was performed by using $0.25 \mathrm{M}$ trimethylsulfonium hydroxide (TMSH) in methanol [47]. FAMEs were determined by capillary gas chromatography on GC Shimadzu 2010 (Kyoto, Japan) equipped with a flame ionization detector and capillary HP-88 column $(100 \mathrm{~m} \times$ $0.25 \mathrm{~mm} \times 0.20 \mu \mathrm{m}, \mathrm{J} \& \mathrm{~W}$ Scientific, USA). The column temperature was programed as follows: initial temperature of $125^{\circ} \mathrm{C}$, rate of $10^{\circ} \mathrm{C} / \mathrm{min}$ to $175^{\circ} \mathrm{C}$, hold for $10 \mathrm{~min}$, and rate of $5{ }^{\circ} \mathrm{C} / \mathrm{min}$ to $210^{\circ} \mathrm{C}$, hold for $5 \mathrm{~min}$, and rate of $2{ }^{\circ} \mathrm{C} / \mathrm{min}$ to a final temperature of $230^{\circ} \mathrm{C}$. Total analysis time was $50.5 \mathrm{~min}$. The injector and detector temperatures were $250{ }^{\circ} \mathrm{C}$ and $280{ }^{\circ} \mathrm{C}$, respectively. The carrier gas was nitrogen at a flow rate of $1.33 \mathrm{~mL} / \mathrm{min}$. Injected volume was $1 \mu \mathrm{L}$, and injector split ratio was 1:50. Nitrogen was used as the make-up gas at a flow rate of $30 \mathrm{~mL} / \mathrm{min}$; detector gases were hydrogen and synthetic air at a rate of $40 \mathrm{~mL} / \mathrm{min}$ and $400 \mathrm{~mL} / \mathrm{min}$, respectively.

The individual FAs were identified using the 37 Component FAME mix standard (Supelco, Bellefonte, USA). The response factors were calculated by the ratios between the peak area of the individual FAME and that of internal standard (heneicosanoic acid methyl ester). Coefficients of variation calculated for seven injections were lower than 5\%. The relative quantities were expressed as the weight percentage of the total FAs.

Quality Control. Reliability and accuracy of the analytical method for the detection of the FAs were ensured by the use of the NIST 3275-2 certified reference material (omega-3 and omega-6 FAs in fish oil, NIST, Gaithersburg, USA) (Table 1).

FA Analysis by Capillary Gas Chromatography by Method 2. Total lipids in fish feed were determined by the application of an organic solvent (AOAC) standard method [21]. Lipids were extracted with petroleum ether (boiling point ranged from 40 to $60{ }^{\circ} \mathrm{C}$ ) after acid hydrolysis of the sample with hydrochloric acid. The FA composition of the samples was determined by gas chromatography. The method used was in situ transesterification [48] as modified by Polak et al. [29]. Briefly, after adding $3 \mathrm{~mL}$ of $0.5 \mathrm{M} \mathrm{NaOH}$ in methanol and $0.3 \mathrm{~mL}$ of methylene chloride to homogenized sample, in situ transesterification was performed by heating sample at $90{ }^{\circ} \mathrm{C}$ for $40 \mathrm{~min}$ and continued heating after adding $14 \% \mathrm{BF}_{3}$ in methanol. The FAMEs were extracted into hexane after cooling and determined by capillary gas chromatography on GC Agilent Technologies 6890 with a flame ionization detector and HP-88 capillary column $(100 \mathrm{~m} \times 0.25 \mathrm{~mm} \times 0.20 \mu \mathrm{m}$, Agilent Technologies). Separation and detection were performed under the following temperature conditions: $150{ }^{\circ} \mathrm{C}$, hold for $10 \mathrm{~min}$, rate of $1.5{ }^{\circ} \mathrm{C} / \mathrm{min}$ to $180{ }^{\circ} \mathrm{C}$, hold for $40 \mathrm{~min}$, and rate of $3{ }^{\circ} \mathrm{C} / \mathrm{min}$ to a final temperature of $240{ }^{\circ} \mathrm{C}$. Total analysis time was $95 \mathrm{~min}$. The injector and detector temperatures were $250{ }^{\circ} \mathrm{C}$ and $280{ }^{\circ} \mathrm{C}$, respectively. The carrier gas was helium at a flow rate of $2.3 \mathrm{~mL} / \mathrm{min}$. Injected volume was $1 \mu \mathrm{L}$, and injector split ratio was 1:30. Nitrogen was used as the make-up gas at a flow rate of $45 \mathrm{~mL} / \mathrm{min}$; detector gases were hydrogen and synthetic air $\left(21 \% \mathrm{O}_{2}\right)$ at a rate of $40 \mathrm{~mL} / \mathrm{min}$ and $450 \mathrm{~mL} / \mathrm{min}$, respectively.

The FAMEs were determined through their retention times in comparison to the relevant standard mixtures using: 37 Components FAME mix (Supelco, Bellefonte, USA); PUFA No. 1, animal source (Supelco, Bellefonte, USA); linoleic acid methyl ester cis/trans isomer Mix (Supelco, Bellefonte, USA); cis-7octadecenoic methyl ester (Supelco, Bellefonte, USA) and cis11-octadecenoic methyl ester (Supelco, Bellefonte, USA); methyl stearidonate (Fluka, Switzerland); and Nu-Chek

Table 1. Amounts of fatty acids $(\mathrm{mg} / \mathrm{g})$ in certified reference material NIST $3275-2$ as stated by manufacturer and quantified by method 1

\begin{tabular}{lccc}
\hline Fatty acids & $\begin{array}{c}\text { NIST 3275-2 reported } \\
\text { by manufacturer }\end{array}$ & $\begin{array}{c}\text { Quantified } \\
\text { by method } 1^{a}\end{array}$ & Recovery \\
\hline C14:0 & $3.45 \pm 0.40$ & $3.43 \pm 0.06$ & 99.4 \\
C16:0 & $8.01 \pm 0.44$ & $7.94 \pm 0.21$ & 99.1 \\
C16:1 & $5.83 \pm 0.45$ & $5.81 \pm 0.15$ & 99.7 \\
C18:0 & $12.94 \pm 0.62$ & $12.85 \pm 0.36$ & 99.3 \\
C18:1 & $22.10 \pm 1.60$ & $21.99 \pm 0.36$ & 99.5 \\
C18:2 & $3.00 \pm 0.42$ & $2.97 \pm 0.16$ & 99.1 \\
C18:3 & $1.42 \pm 0.12$ & ND & \\
C20:5 & $394 \pm 17$ & $424 \pm 10$ & 107.6 \\
C22:5 & $67.6 \pm 2.3$ & $67.1 \pm 2.0$ & 99.3 \\
C22:6 & $187 \pm 8$ & $189 \pm 6$ & 101.1 \\
ND, not detected. & & \\
${ }^{a}$ Extraction of lipids. & & \\
\hline
\end{tabular}


standards GLC-68D, GLC-85, and GLC-411 (Nu-Chek, Minnesota, USA). The GLC-68D and GLC-85 standard mixtures were used to determine the response factor for each FA. The weight of each FA in the sample was determined using the response factor and the transformation factor of the FA content from the FAME content. The samples were analyzed in duplicate. The FAMEs were expressed as weight percentages of the total FA content.

Quality Control. Reliability and accuracy of the analytical method for the detection of the FAs were ensured by the use of the CRM BCR-163 certified reference material (beef-pork blend fat, IRMM, Geel, Belgium) (Table 2).

Statistical Analysis. Precision for the comparative study was derived from statistical analysis according to ISO procedure [49]. Two fish and one fish feed samples containing different amounts of PUFAs were analyzed in duplicate, and the mean values of each measurement were used for statistical evaluation. In order to compare the statistics obtained with the different variables, the reproducibility values $(R)$ were calculated and compared for each FA according to ISO [49] and AOAC [15] procedures. These procedures stated accuracy and reproducibility necessary for accurate determination of the FA composition, according to which the majority of the FAs (>5\%) allowed limit not more than $3 \%$ absolutely in the samples of fats and oils of animal origin. The ISO [49] procedure states the reproducibility for constituents present in smaller amounts; the difference should not exceed $0.5 \%$ of the absolute value.

\section{Results and Discussion}

Results showed that the laboratories had very good interlaboratory control of their methods (Tables 1 and 2). Altogether,

Table 2. Amounts of fatty acids $(\mathrm{g} / 100 \mathrm{~g})$ in certified reference material BCR-163 as stated by manufacturer and quantified by method 2

\begin{tabular}{lcrr}
\hline Fatty acids & $\begin{array}{c}\text { BCR-163 reported } \\
\text { by manufacturer }\end{array}$ & $\begin{array}{c}\text { Quantified by } \\
\text { method 2 }\end{array}$ & Recovery \\
\hline C14:0 & $2.29 \pm 0.04$ & $2.3 \pm 0.11$ & 100.4 \\
C16:0 & $25.96 \pm 0.30$ & $25.88 \pm 0.22$ & 99.7 \\
C16:1 & $2.58 \pm 0.16$ & $2.73 \pm 0.08$ & 105.8 \\
C18:0 & $18.29 \pm 0.16$ & $18.11 \pm 0.25$ & 99.0 \\
C18:1 & $38.34 \pm 1.36$ & $38.45 \pm 0.45$ & 100.3 \\
C18:2 & $7.05 \pm 0.17$ & $7.12 \pm 0.12$ & 101.0 \\
C18:3 & $0.86 \pm 0.14$ & $0.88 \pm 0.08$ & 102.3 \\
${ }^{a}$ In situ transesterification. & & \\
\hline
\end{tabular}

18 and 19 FAs per fish were detected by method 1 and method 2 , respectively. Detected FAs are those for which the laboratories reported mean FA weight percent values greater than zero. Laboratory 1 (method 1) ignored very small peaks in their chromatograms (less than $0.1 \%$ ), while laboratory 2 (method 2) did not ignore any peaks. Laboratory 1 had overlapping peaks for FAs C22:1n-9 and C20:4n-6, while laboratory 2 had overlapping peaks for FAs C20:4n-6 and C20:3n-3.

Smith and Hansen [50] found higher reproducibility level for analytes that were present at moderate concentrations due to serious overlap of analyte peaks. Therefore, the same peaks were compared in Table 3 for the FAs in fish and in Table 4 for the FAs in fish feed. In situ transesterification and saponification method were found to be suitable for determination of FAs with high recovery and sensitivity for PUFAs [38]. Also, there was

Table 4. Results and uncertainties of the fatty acid composition (\% of total fatty acids) and total fat content in fish feed as reported by laboratories

\begin{tabular}{|c|c|c|c|c|}
\hline Fatty acids & Meth 1 & Meth 2 & $R$ & $R$ \\
\hline$\overline{\mathrm{C} 14: 0}$ & $1.73 \pm 0.01$ & $2.09 \pm 0.01$ & -0.36 & NS \\
\hline C15:0 & $0.13 \pm 0.00$ & $0.16 \pm 0.00$ & -0.03 & NS \\
\hline C16:0 & $12.91 \pm 0.02$ & $13.05 \pm 0.01$ & -0.14 & NS \\
\hline $\mathrm{C} 16: 1 n-7$ & $2.99 \pm 0.01$ & $2.86 \pm 0.01$ & 0.13 & NS \\
\hline $\mathrm{C} 17: 0$ & $0.25 \pm 0.00$ & $0.04 \pm 0.00$ & 0.21 & NS \\
\hline C18:0 & $2.90 \pm 0.02$ & $3.35 \pm 0.01$ & -0.45 & NS \\
\hline C18:1cis-9 & $43.63 \pm 0.01$ & $41.32 \pm 0.04$ & 2.31 & NS \\
\hline $\mathrm{C} 18: 2 n-6$ & $18.63 \pm 0.01$ & $18.14 \pm 0.02$ & 0.49 & NS \\
\hline $\mathrm{C} 20: 0$ & $0.71 \pm 0.00$ & $0.31 \pm 0.01$ & 0.40 & NS \\
\hline C18:3n-6 & - & $0.09 \pm 0.00$ & -0.09 & NS \\
\hline C18:3n-3 & $4.89 \pm 0.01$ & $5.02 \pm 0.02$ & -0.13 & NS \\
\hline C20:1cis-11 & $4.81 \pm 0.01$ & $3.03 \pm 0.01$ & 1.78 & NS \\
\hline $\mathrm{C} 20: 2 n-6$ & $0.77 \pm 0.00$ & $0.69 \pm 0.00$ & 0.08 & NS \\
\hline $\mathrm{C} 20: 3 n-6$ & $0.22 \pm 0.00$ & $0.19 \pm 0.00$ & 0.03 & NS \\
\hline C20:4n-6 & o & $0.77 \pm 0.01$ & - & - \\
\hline $\mathrm{C} 22: 1 n-9$ & o & $0.48 \pm 0.00$ & - & - \\
\hline $\mathrm{C} 20: 5 n-3$ & $1.92 \pm 0.00$ & $2.38 \pm 0.02$ & -0.46 & NS \\
\hline $\mathrm{C} 22: 5 n-3$ & $0.76 \pm 0.00$ & $0.02 \pm 0.00$ & 0.74 & NS \\
\hline$C 22: 6 n-3$ & $3.00 \pm 0.01$ & $3.12 \pm 0.03$ & 0.12 & NS \\
\hline $\mathrm{C} 22: 0$ & - & 0.190 .00 & -0.19 & NS \\
\hline $\mathrm{C} 24: 0$ & $0.20 \pm 0.00$ & $0.58 \pm 0.00$ & -0.38 & NS \\
\hline Total lipids, \% & $17.31 \pm 0.15$ & $17.19 \pm 0.04$ & 0.12 & NS \\
\hline \multicolumn{5}{|c|}{$\begin{array}{l}\text { Values are reported as mean } \pm \text { standard deviation; Meth } 1 \text {, method } 1- \\
\text { extraction of lipids; Meth } 2 \text {, method } 2-\text { in situ transesterification; } R \text {, } \\
\text { reproducibility; NS, not significant for major constituents } R \leq 3 \% \text {; } \\
\text { NS, not significant for minor constituents } R \geq 0.5 \% \text {; overlapping } \\
\text { peaks; for total lipids: NS, not significant } R \leq 0.5 \% \text {. }\end{array}$} \\
\hline
\end{tabular}

Table 3. Results and uncertainties of the fatty acid composition (\% of total fatty acids) and total fat content in fish as reported by laboratories

\begin{tabular}{|c|c|c|c|c|c|c|c|c|}
\hline Fatty acids & $\mathrm{Z1}$ & $\mathrm{Z2}$ & Š1 & Š2 & $R \mathrm{Z}$ & $R \breve{\mathrm{S}}$ & $R \mathrm{Z}$ & $R \check{\mathrm{S}}$ \\
\hline C14:0 & $1.17 \pm 0.00$ & $1.07 \pm 0.02$ & $1.47 \pm 0.00$ & $1.62 \pm 0.03$ & 0.10 & -0.15 & NS & NS \\
\hline $\mathrm{C} 15: 0$ & $0.11 \pm 0.01$ & $0.10 \pm 0.01$ & $0.14 \pm 0.00$ & $0.14 \pm 0.00$ & 0.01 & 0.00 & NS & NS \\
\hline $\mathrm{C} 16: 0$ & $12.69 \pm 0.01$ & $11.15 \pm 0.47$ & $11.96 \pm 0.03$ & $11.20 \pm 0.03$ & 1.54 & 0.76 & NS & NS \\
\hline C16:1n-7 & $2.05 \pm 0.01$ & $1.56 \pm 0.03$ & $2.46 \pm 0.01$ & $2.30 \pm 0.02$ & 0.49 & 0.16 & NS & NS \\
\hline C17:0 & $0.17 \pm 0.00$ & $0.16 \pm 0.00$ & $0.18 \pm 0.00$ & $0.21 \pm 0.00$ & 0.01 & -0.03 & NS & NS \\
\hline C18:0 & $3.44 \pm 0.01$ & $2.75 \pm 0.11$ & $3.21 \pm 0.10$ & $2.88 \pm 0.03$ & 0.69 & 0.33 & NS & NS \\
\hline C18:1cis-9 & $39.04 \pm 0.04$ & $37.21 \pm 1.30$ & $46.07 \pm 0.03$ & $43.27 \pm 0.08$ & 1.83 & 2.80 & NS & NS \\
\hline C18:2n-6 & $15.11 \pm 0.01$ & $14.96 \pm 0.33$ & $16.78 \pm 0.06$ & $18.52 \pm 0.17$ & 0.15 & -1.74 & NS & NS \\
\hline $\mathrm{C} 20: 0$ & $0.17 \pm 0.00$ & $0.07 \pm 0.06$ & $0.22 \pm 0.00$ & $0.32 \pm 0.00$ & 0.10 & -0.10 & NS & NS \\
\hline$C 18: 3 n-6$ & $0.30 \pm 0.01$ & $0.00 \pm 0.00$ & $0.43 \pm 0.00$ & $0.42 \pm 0.01$ & 0.30 & 0.01 & NS & NS \\
\hline C18:3n-3 & $1.41 \pm 0.01$ & $2.77 \pm 0.02$ & $1.67 \pm 0.06$ & $3.05 \pm 0.07$ & -1.36 & -1.38 & NS & NS \\
\hline C20:1cis-11 & $3.87 \pm 0.01$ & $2.27 \pm 0.11$ & $3.81 \pm 0.02$ & $2.57 \pm 0.10$ & 1.60 & 1.24 & NS & NS \\
\hline C20:2n-6 & $0.76 \pm 0.01$ & $0.80 \pm 0.02$ & $0.94 \pm 0.00$ & $1.00 \pm 0.01$ & -0.04 & -0.06 & NS & NS \\
\hline$C 20: 3 n-6$ & $0.53 \pm 0.01$ & $0.66 \pm 0.02$ & $0.46 \pm 0.00$ & $0.63 \pm 0.01$ & -0.13 & -0.17 & NS & NS \\
\hline $\mathrm{C} 20: 3 n-3$ & $0.64 \pm 0.01$ & o & $0.97 \pm 0.01$ & o & - & - & - & - \\
\hline C20:4n-6 & o & $1.12 \pm 0.02$ & o & $0.84 \pm 0.10$ & - & - & - & - \\
\hline $\mathrm{C} 22: 1 n-9$ & o & $0.53 \pm 0.03$ & o & $0.35 \pm 0.02$ & - & - & - & - \\
\hline$C 22: 5 n-3$ & $1.02 \pm 0.02$ & $1.10 \pm 0.04$ & $0.29 \pm 0.01$ & $0.62 \pm 0.14$ & -0.08 & -0.33 & NS & NS \\
\hline$C 22: 6 n-3$ & $14.75 \pm 0.01$ & $17.56 \pm 0.04$ & $6.85 \pm 0.01$ & $7.01 \pm 0.05$ & -2.81 & -0.16 & NS & NS \\
\hline Total lipids, $\%$ & $2.44 \pm 0.07$ & $1.75 \pm 0.39$ & $6.51 \pm 0.08$ & $6.23 \pm 0.21$ & 0.69 & 0.28 & $* * *$ & NS \\
\hline
\end{tabular}

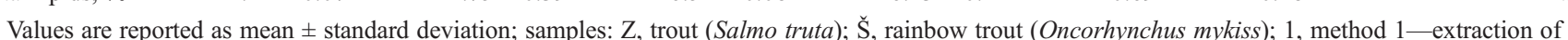
lipids; 2, method 2-in situ transesterification; $R$, reproducibility; NS - not significant for major constituents $R \leq 3 \%$; $R \geq 3 \%$; NS - not significant for minor constituents $R \geq 0.5 \%$; o - overlapping peaks; for total lipids: NS - not significant $R \leq 0.5 \%,{ }^{* * * *} R \geq 0.5 \%$. 
good correspondence between FA composition determined by direct methylation and by Folch extraction prior to the methylation step [28]. Statistical analysis of the results of FA composition and total lipids content in the two fish samples and fish feed with uncertainties are presented in Table 3.

The reproducibility $(R)$ values for the majority of FAs that were analyzed in this study were less than $3 \%$ of absolute values [49], i.e., less than the maximum allowable difference. Mean values for the contents of oleic acid (C18:1 cis-9) were more varied between the two laboratories in both fish samples, but the difference was not higher than $3 \%$ of the absolute values. However, for the mean values of $\mathrm{C} 18: 1$ cis- 9 and $\mathrm{C} 18: 2 n-6$, significant differences were observed between a greater number of laboratory groups in Iberian pork fat [51]. Other monounsaturated fatty acids (MUFAs) like C16:1n-7 and C20:1 had a very good $R$ values (lower than $0.5 \%$ ).

As can be observed (Table 3), the $R$ values for the saturated fatty acids (SFAs) (C14:0, C15:0, C17:0, C18:0, and C20:0) were less than $0.5 \%$ for the minor constituents in both fish samples. The $R$ value for palmitic acid (C16:0), the most abundant of the SFAs, was less than $3 \%$ of the absolute value. $R$ values for the $n-6$ polyunsaturated fatty acids (PUFAs) (C18:2n-6, $\mathrm{C} 18: 3 n-6,20: 3 n-6$, and $\mathrm{C} 20: 2 n-6)$ were less than $3 \%$ for major constituents and less than $0.5 \%$ for minor constituents. $R$ values for the $n-3$ PUFAs (C18:3n-3, C20:5n-3, and C22:6n-3) were less than $3 \%$ for major constituents $(\mathrm{C} 18: 3 n-3,-1.36,-1.38$; $\mathrm{C} 20: 5 n-3,-1.08,-0.48$; $\mathrm{C} 22: 6 n-3,-2.81,-0.16$ in fish $\mathrm{Z}$ and in fish $\breve{S}$, respectively). Differences in calculating ionization detector response factors in the laboratories could lead to variation in the results, especially for $\mathrm{C} 22: 6 n-3$. However, differences in the contents of C20:5n-3 (EPA) and C22:6n-3 (DHA) might be due to calibration errors of the gas chromatographic methods with the calibration standards and/or possibly in the correction factor used. Empirical correction factor must be adapted for accurate EPA and DHA analyses conducted at temperatures causing thermal losses [52]. Also, a major potential source of loss of PUFAs might be autoxidation caused by faulty sample-handling [13]. Difficulties in determining EPA and DHA have been reported in marine and other oils [50].

It can be concluded that adequate accuracy of the FA composition of fish was achieved in this study. Higher $R$ values for the total lipids content $(>5 \%)$ and the FA composition in fish $\mathrm{Z}$ than in fish $\breve{S}$ might might be a consequence of greater variability of the fish $\mathrm{Z}$ samples. This is confirmed by the reproducibility limit of the total fat determination in fish by ISO procedure [19]. An $R$ value higher than $0.5 \%$ was obtained in fish $\mathrm{Z}(0.69 \%)$, while it was smaller in fish Š $(0.28 \%)$. According to Horwitz [34], gravimetric determination of the total fat content in meat with a higher fat content resulted in a higher coefficient of variation (\%) and a higher standard deviation than did determination of the same in meat with a lower fat content. On the other hand, Smith and Hansen [50] reported that $R$ values worsen for analytes below $0.5 \%$ (weight percent) or less. It is not easy to give an objective assessment of the standard of accuracy that should be possible in routine analyses of FAs, but in a collaborative study of International Union of Pure and Applied Chemistry (IUPAC) methodology for FA analysis, typical coefficients of variation (\%) at various concentrations were 15 for $2 \%$ level of FAs, 8.5 for $5 \%$ level of FAs, 7 for $10 \%$ level of FAs, and 3 for $50 \%$ level of FAs [13].

Statistical analysis of the results of FA composition and total lipids content in the fish feed with uncertainties are presented in Table 4.

The $R$ values of the main FAs (present in feed in amounts $>5 \%)$ ranged from $-1.14(\mathrm{C} 16: 0)$ to $1.23(\mathrm{C} 18: 2 n-6)$ in the fish feed. The $R$ values of the $n-3$ PUFAs ranged between -1.06 (C20:5n-3) and 0.97 (C22:6n-3). The difference expressed as $R$ value of the total lipids content was not significant $(0.12 \%)$. The mean values for the content of oleic acid (C18:1cis-9) also varied between the two laboratories, similar to oleic acid measurements in the fish. $R$ values of the $n-3$ PUFAs (C18:3n-3, $\mathrm{C} 20: 5 n-3$ and $\mathrm{C} 22: 6 n-3)$ were lower than $3 \%$ in the fish feed and differences were not significant.

To enable comparison of the two different methods, and taking into account the stricter criteria of the method for analyses of animal and vegetable fats and oils by gas chromatography without a total extraction step, correlation between the FA composition of fish and feed was performed in two laboratories. Pearson's correlation coefficient for fish $\mathrm{Z}$ and fish Š were $r=0.987$ and $r=0.994$, respectively. Corresponding $t$ values were 37.50 and $54.65\left(t_{\text {crit }}=2.09, P=0.05\right)$, indicating a statistically significant correlation between the FA composition of the fish determined in the two laboratories. The obtained correlation coefficient and corresponding $t$ values for FA composition indicated worse precision and probably higher variability of fish Z samples in both laboratories. Higher correlation coefficient and $t$ values were obtained for fish $\breve{\mathrm{S}}$ samples in both laboratories as well as for between-laboratory performances, i.e., $R$ values.

Pearson's correlation coefficient for the fish feed was $r=0.997$. The $t$ value was $78.06\left(t_{\text {crit }}=2.09, P=0.05\right)$, indicating a statistically significant correlation between the FA composition of the fish feed determined in two laboratories.

The FA contents in the two fish species and feed sample analyzed in laboratories were very similar, with the exception of the FA C18:1 cis-9 (somewhat higher content measured by method 1) and C22:6n-3 (higher content measured in both fish by method 2). According to our knowledge, there were two collaborative studies organized for the determination of $n-3$ and $n-6$ fatty acids in vegetable fats and oils by capillary gas chromatography [53]. It was found rather high reproducibility coefficient of variation, but overall, the results were satisfactory [53].

Results of reproducibility obtained for the most of the FAs in the fish samples showed that the accuracy of the gas chromatography methods used were adequate for the analysis of fish. Similar reproducibility values of the total lipids content and FA composition in fish feed were observed. At the same time, the methods for extracting the total lipids content with either application of an organic solvent or the in situ methylation method resulted in statistically almost equal composition of most of the FAs.

\section{Conclusion}

The reproducibility values of the majority of FAs analyzed in this study were less than values recommended by the ISO standard method as a maximum allowable difference. Therefore, adequate accuracy was obtained in this study for quantification of most of the FAs. Reproducibility of most of the FAs in the fish showed that the accuracy of the gas chromatography with flame ionization detection was suitable and adequate for quantification of these compounds in this animal tissue matrix. The FA contents in the two fish species and feed sample analyzed in laboratories were very similar, with the exception of the FA C18:1cis-9 (somewhat higher content measured by method 1) and C22:6n-3 (higher content measured in both fish by method 2). At the same time, the two methods for extracting total lipids (ASE and AOAC) produced statistically equal content of total lipids in the fish and the fish feed. Reproducibility values of the in situ transesterification method and extraction of lipids with transesterification followed by gas chromatography with flame ionization detector were satisfactory for most of the FAs. Overall, adequate accuracy was obtained in this study. The proposed method provides a fast and efficient means of identifying fish and feed for quality control purposes.

Acknowledgments. This work was supported by the Bilateral project (project no. 405-03-3095/2014-09/49) funded 
by the Ministry of Education, Science and Technological Development of the Republic of Serbia. The authors are grateful for financial support from the Ministry of Higher Education, Science and Technology of the Republic of Slovenia via the Bilateral project BI-RS/14-15-058.

\section{References}

1. Caballero, M. J.; Obach, A.; Rosenlund, G.; Montero, D.; Gisvold, M.; Izquierdo, M. S. Aquaculture 2002, 214, 253-271.

2. Menoyo, D.; López-Bote, C. J.; Diez, A.; Obach, A.; Bautista, J. M. Aquaculture 2007, 267, 248-259.

3. Jobling, M.; Leknes, O.; Seather, B. S.; Bendiksen, E. A. Aquaculture 2008, 281, 87-94.

4. Turchini, G. M.; Torstensen, B. E.; Ng, W.-K. Rev. Aquacult. 2009, 1, $10-57$.

5. Grigorakis, K.; Alexis, M. N.; Taylor, K. D. A.; Hole, M. Int. J. Food Sci. Tech. 2002, 37, 477-484.

6. Skalli, A.; Robin, J. H.; Le Bayon, N.; Le Delliou, H.; Person-Le Ruyet, J. Aquaculture 2006, 255, 223-232.

7. Valente, L. M. P.; Bandarra, N. M.; Figueiredo-Silva, A. C.; Rema, P.; Vaz-Pires, P.; Martins, S.; Prates, J. A. M.; Nunes, M. L. Brit. J. Nutr. 2007, 97, 289-297.

8. Robin, J. H.; Skalli, A. Aquaculture 2007, 263, 227-237.

9. Rasoarahona, J. R. E.; Barnathan, G.; Bianchini, J. P.; Gaydou, E. M. J. Agr. Food Chem. 2004, 52, 7339-7344.

10. Kiessling, A.; Pickova, J.; Johansson, L.; Asgard, T.; Storebakken, T.; Kiessling, K. H. Food Chem. 2001, 73, 271-284.

11. Alasalvar, C.; Taylor, K. D. A.; Zubcov, E.; Shahidi, F.; Alexis, M Food Chem. 2002, 79 145-150.

12. Jensen, K. N.; Jacobsen, C.; Nielsen, H. H. J. Sci. Food Agr. 2007, 87, $710-718$.

13. Christie, W. W. Lipid Analysis; The Oily Press: Bridgwater, 2003, 432

14. Ackman, R. G. Progr. Food Nutr. Sci. 1989, 13, 161-289.

15. AOAC 963.22. Official Methods of Analysis of the AOAC, 17th Ed.; Arlington, Virginia: USA, 2000

16. Carvallo, A. P.; Malcata, F. X. J. Agr. Food Chem. 2005, 53, 5049-5059.

17. Schreiner, M. J. Chromatogr. A. 2005, 1095, 126-130.

18. Schreiner, M.; Hulan, H. W. J. Chromatogr. A. 2004, 1045, 197-202.

19. ISO 1443: Meat and meat products - Determination of total fat content 1973

20. ISO 6492: Animal feeding stuffs - Determination of fat content 1999.

21. AOAC 991.36. Official Methods of Analysis of the AOAC 17th Ed.

Arlington, Virginia: USA 2000

22. Folch, J.; Lees, M.; Stanley, G. H. S. J. Biol. Chem. 1957, 226, 497-509.

23. Blight, E. G.; Dyer, W. J. Can. J. Biochem. Physiol. 1959, 37, 911-917.

24. Hara, A.; Radin, N. S. Anal. Biochem. 1978, 90, 420-426.
25. Shäfer, K. Anal. Chim. Acta 1998, 358, 69-77.

26. Dodds, E. D.; Mc Coy, R. M.; Geldenhuys, A.; Rea, D. L.; Kennish, J. M. J. Am. Oil Chem. Soc. 2004, 81, 835-840.

27. Carrapiso, A. I.; García, C. Lipids 2000, 35, 1167-1177.

28. Meier, S.; Mjøs, S. A.; Joensen, H.; Grahl-Nielsen, O. J. Chromatogr. A 2006, 1104, 291-298.

29. Polak, LT.; Rajar, A.; Gašperlin, L.; Žlender, B. Meat Sci. 2008, 80 , 864-869.

30. Ichihara, K.; Fukubayashi, Y. J. Lipid Res. 2010, 51, 635-640.

31. Ackman, R. G. Anal. Chim. Acta 2002, 465, 175-192.

32. Craske, J. D.; Bannon, C. D. J. Am. Oil Chem. Soc. 1987, 64, 1413-1417.

33. Bannon, C. D.; Craske, J. D.; Hilliker, A. E. J. Am. Oil Chem. Soc. 1986, 63, 105-110.

34. Horwitz, W. Anal. Chem. 1982, 54, 67A-76A

35. Venelinov, T.; Quevauviller, Ph. Trac-Trend Anal. Chem. 2003, 22, 15-18.

36. Prichard, E.; Barwick, V. Quality assurance in analytical chemistry; LGC Limited: Teddington, 2007.

37. Danzer, K. Analytical Chemistry: Theoretical and metrological fundamentals; Springer-Verlag: Berlin, Heidelberg, 2007.

38. Juárez, M.; Polvillo, O.; Contò, M.; Ficco, A.; Ballico, S.; Failla, S. J. Chromatog. A 2008, 1190, 327-332.

39. Igarashi, T.; Aursand, M.; Hirata, Y.; Gribbestad, I. S.; Wada, S.; Nonaka, M. J. Am. Oil Chem. Soc. 2000, 77, 737-748.

40. Zhurkovich, I. K.; Mil'man, B. L. J. Anal. Chem. 2009, 64, 1012-1021. 41. Schantz, M. M.; Sander, L. C.; Sharpless, K. E.; Wise, S. A.; Yen, J. H.; NguyenPho, A.; Betz, J. M. Anal. Bioanal. Chem. 2013, 405, 4531-4538.

42. Zenkevich, I. G.; Eshchenko, A. Yu.; Klimova, I. O. J. Anal. Chem. 2005, 60, 119-124.

43. Kucklick, J. R.; Schantz, M. M.; Pugh, R. S.; Porter, B. J.; Poster, D. L.; Becker, P. R.; Rowles, T. K.; Leigh, S.; Wise, S. A. Anal. Bioanal. Chem. 2010, 397, 423-432.

44. Welch, M. J.; Colbert, J. C.; Gill, L. M.; Phinney, C. S.; Sharpless, K. E.; Sniegoski, L. T.; Wood, L. J. J. Anal. Chem. 2001, 370, 42-47.

45. Zschunke, A. Reference Materials in Analytical Chemistry: A Guide for Selection and Use; Springer-Verlag: Heidelberg, Berlin, 2000, 222.

46. ISO 3100-1: Meat and meat products - Sampling and preparation of test samples - Part 1: Sampling 1991.

47. EN ISO 5509: Animal and vegetable fats and oils - Preparation of methyl esters of fatty acids $\mathbf{2 0 0 0}$.

48. Park, P. W.; Goins, R. E. J. Food Sci. 1994, 59, 262-1266.

49. ISO 5508: Animal and vegetable fats and oils - Analysis by gas chromatography of methyl esters of fatty acids $\mathbf{1 9 9 0 .}$

50. Smith, S. A.; Hensen, S. L. J. Am. Oil Chem. Soc. 2008, 85, 901-909.

51. García-Olmo, J.; De Pedro, E.; Garrido, A.; Paredes, A.; Sanabria, C.; Santolalla, M.; Salas, J.; García-Hierro, J. R.; Gonzalez, I.; García-Cachan, M. D.; Guirao, J. Meat Sci. 2002, 60, 103-109.

52. Ackman, R. G. J. Am. Oil Chem. Soc. 2006, 83, 1069.

53. Beare-Rogers, J. L.; Dieffenbacher, A. Pure Appl. Chem. 1990, 62, 795-802. 